\title{
Interest of Systematic Chest Radiography during Periodic Medical Visits in Workers
}

\author{
Mathurin Neossi Guena1,2*, Romai Batchago Tchouezoue1, Florent Zilbinkai Alapha², \\ Jérémie Mbo Amvene ${ }^{3}$, Joseph Gonsu Fotsing ${ }^{4,5}$
}

\author{
${ }^{1}$ Department of Biomedical Sciences, Faculty of Sciences, University of Ngaoundéré, Ngaoundéré, Cameroon \\ ${ }^{2}$ Imaging service, Ngaoundéré Regional Hospital, Ngaoundéré, Cameroon \\ ${ }^{3}$ Faculty of Medicine and Biomedical Sciences, University of Ngaoundere, Garoua, Cameroon \\ ${ }^{4}$ Faculty of Medicine and Biomedical Sciences, University of Yaounde I, Yaounde, Cameroon \\ ${ }^{5}$ Yaounde Gynaecology Obstetrics and Pediatrics Hospital, Yaounde, Cameroon \\ Email: *mneossiguena@yahoo.fr
}

How to cite this paper: Guena, M.N. Tchouezoue, R.B., Alapha, F.Z., Amvene, J.M. and Fotsing, J.G. (2019) Interest of Systematic Chest Radiography during Periodic Medical Visits in Workers. Advances in Molecular Imaging, 9, 43-52.

https://doi.org/10.4236/ami.2019.93004

Received: April 28, 2019

Accepted: June 14, 2019

Published: June 17, 2019

Copyright (c) 2019 by author(s) and Scientific Research Publishing Inc. This work is licensed under the Creative Commons Attribution International License (CC BY 4.0).

http://creativecommons.org/licenses/by/4.0/

\begin{abstract}
Background: Systematic chest X-ray is the most prescribed examination by occupational physicians during periodic medical check-ups in our context, unlike in most countries where this practice has been discontinued. Objective: The objective was to determine the diagnostic yield and cost-effectiveness of chest radiography during periodic medical check-ups of workers in Ngaoundere. Materials and Methods: A cross-sectional and descriptive study was carried out in Ngaoundere Regional Hospital from January to December 2018, concerning all persons coming to perform a systematic chest X-ray in the context of the periodic medical check-up having been consented to participate in the study. Posteroanterior (PA) chest radiographs were obtained from all workers during this periodic medical check-up. The variables studied were: age, sex, clinical manifestations, antecedents, job type, cost, and chest $\mathrm{X}$-ray results. Statistical analysis was performed using the Sphinx Plus'-Lexica-V5 Edition software. Results: 753 workers were selected for this study, of whom $88.04 \%$ were men and $11.96 \%$ were women, a sex ratio $\mathrm{H} / \mathrm{F}$ is of 7.4 , the average age was $39 \pm 7.89$ years with extremes of 24 and 56 years, the most frequent job type was the administration (38.37\%), the storekeepers (17.92) and the drivers (15.27\%), most of them were asymptomatic (97.47\%), some had cough $(2.52 \%)$, chest pain $(2.12 \%)$, dyspnea $(0.26 \%)$ and fever $(0.13 \%)$. History was dominated by lung infection (2.39\%), pleurisy (1.06\%) and tuberculosis $(0.79 \%) .7 .43 \%$ of workers occasionally smoked tobacco and consumed alcohol. 41 cases of pathologies (5.44\%) were found on the chest X-ray, including 1 case $(0.13 \%)$ of evolutionary pathology, 40 cases $(5.31 \%)$ of sequelae pathologies. When the results of the chest X-ray are compared with the clini-
\end{abstract}


cal signs and the pathological history of the workers, it is found that the only case with evolutionary abnormalities on the chest X-ray showed clinical signs and that the other cases with sequelae abnormalities had either clinical signs or antecedents related to these abnormalities. The cost of a chest X-ray at the time of our study was 5,000 FCFA (\$8.59), for a total of 3,765,000 FCFA (\$6473.74) for all the X-rays performed. Conclusion: In view of the low rate of abnormalities on the chest X-ray and the sequelae nature of the pathologies, it can be said that the routine X-ray of the chest during the periodic medical check-ups has a low diagnostic yield and a low cost-effectiveness ratio and is not profitable. It should be non-systematic and case-by-case based on the clinical context and background of workers.

\section{Keywords}

Chest X-Ray, Workers, Periodic Medical Check-Ups, Diagnostic Value, Cost

\section{Introduction}

The periodic medical examination is a visit to which the employee is subjected in the course of his employment, carried out by the working doctor, on which the company depends. This is the central element of worker health surveillance. Prescribed by law, its purpose is to pronounce on the suitability or incapacity of the worker at the job type and to ensure that he does not present any contagious disease that could endanger the health of other workers [1]. During these periodic medical examinations, the occupational doctor carries out an interrogation, the clinical examination, and can carry out or prescribe the additional examinations necessary for the determination of the compatibility between the job type and the state of health of the worker, including the detection of conditions that may lead to a contre-indication to this job, an occupational disease that may result from the professional activity of the worker and the detection of dangerous diseases for the professional environment of the worker. The regulation does not specify the examinations to be performed during the periodic medical visits, thus leaving the choice to the doctor to prescribe the examinations according to the risk and the epidemiological context [2]. Of all the complementary examinations, the chest radiography is certainly the most prescribed by the occupational physicians. Its usual justification outside any occupational exposure is the search for undifferentiated tuberculosis [3]. Adekol et al. in a study on routine chest $\mathrm{X}$-ray in pre-employment medical examination for healthcare workers found a single abnormality that was cardiomegaly in $4.8 \%$, so $66 \%$ was over 41 years old therefore significantly associated with age, he therefore concluded that this practice was not necessary and should be reserved for older workers [4]. Moifo et al. in a study assessing the role of routine chest X-ray in asymptomatic students during university enrollment in a tuberculosis-endemic area find that this practice has low diagnostic yield and is therefore not profitable in a context where 
resources are limited [5]. X-rays of the chest are probably the screening test whose prescription has decreased the most in France helped by the abandonment of its systematic prescription in occupational medicine, obstetrics or preoperatively, the current consensus in France is not to ask for routine radiography under 60 years old [6]. Indeed its reading is difficult and not free of false negatives and especially false positives, resulting in the prescription of additional exams heavy and unnecessary. In some countries, this examination is in great demand by the employees, firstly because of the high proportion of smokers in the workplace who wish to self-control, but also because those workers would like to have a certain advantage at the expense of the employer. For the occupational physicians, the experience of systematic prescriptions for chest X-rays does not show any particular benefit, especially for areas where no potential respiratory risk is to be monitored [6]. Zima-Ebeyard et al. in a study entitled Interest of Systematic Diagnostic Radiology of the chest during Periodic Medical Visits (PMV) among workers in Gabon, found a high performance for screening for tuberculosis and low for lung cancer, they therefore propose that thoracic radiography should be performed on a case-by-case basis and should be preceeded by a clinical examination including a thorough anamnesis and in particular a good interview on known occupational and environmental exposures [3]. The last similar study carried out in our country dates back to 1998 by Nouthe Djudgang et al. who arrived at the same conclusion [7]. Yet in our country the practice of routine chest X-ray in medical periodic visits is still very common, practically requested routinely by almost all working physicians, despite the abandonment by many countries. Thus, we proposed to evaluate the interest of this practice in the follow-up of the workers in our context, in particular as regards the diagnostic yield and the cost-effectiveness ratio.

\section{Materials and Methods}

It was a cross-sectional descriptive study conducted at the Ngaoundéré Regional Hospital, during a year from January to December 2018, including all persons coming to perform a routine chest X-ray as part of periodic medical visits and who agree to participate in the study, were excluded those who refused to participate in the study and pregnant women for whom X-ray radiographs were contraindicated. A preliminary examination and clinical examination were performed by occupational physicians to search for any underlying illness and the medical history of the person concerned. A chest X-ray with a single posterioranterior (PA) incidence was then obtained in the radiology and medical imaging department after presenting a request form. The technician after performing the $\mathrm{X}$-ray check the quality before interpretation by a radiologist doctor with a great experience in the interpretation of chest X-rays. The following variables were studied: name, age, sex, workstation, clinical results and chest X-ray results. After interpretation we coded the results of the chest X-ray as normal, sequelae anomaly and evolutionary anomaly depending on the need or not for a comple- 
mentary assessment. The results of the chest X-ray were confronted with the clinic and the antecedents. The cost of an X-ray was the one applied in this hospital at the time of the study in local currency which is the Communauté Financière Africaine franc (F CFA). This cost was converted into United States dollars (\$) using the exchange rate prevailing at the time of the study. Data were collected with the aid of a standardized questionnaire. The collected data were analyzed statistically using the Sphinx V5 Edition statistical software.

\section{Results}

A total of 753 workers were enrolled. There were 663 men (88.04\%) and 90 women $(11.96 \%)$, giving a sex ratio of $7: 37$. The mean age of the study population was 39 years, with a minimum of 26 years and a maximum of 56 years (Figure 1).

Workers were mostly administrative staff with $38.37 \%$, drivers with $17.92 \%$, storekeepers with $15.27 \%$ and technicians with $7.43 \%$ (Table 1).

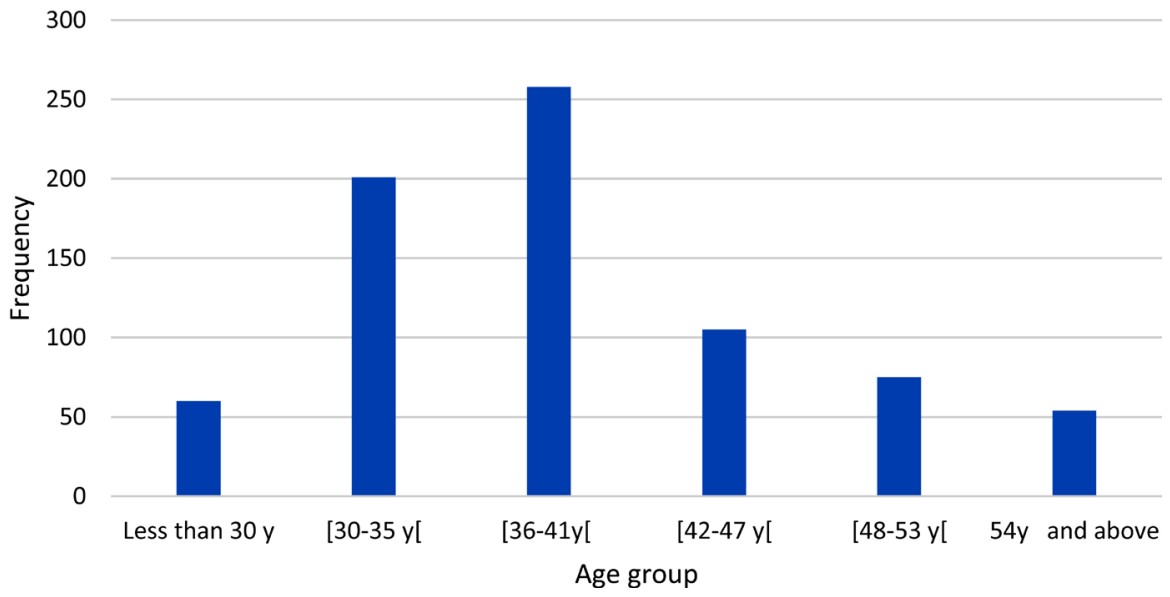

Figure 1. Distribution of patients by age.

Table 1. Distribution by job type.

\begin{tabular}{ccc}
\hline Profession & Frequency & Percentage (\%) \\
\hline Administration & 289 & 38.37 \\
Driver & 135 & 17.92 \\
Storekeeper, handling work & 115 & 15.27 \\
Technician & 56 & 7.43 \\
Accountant & 40 & 5.31 \\
Cashier & 33 & 4.38 \\
Mechanic & 1 & 2.52 \\
Watchman & 15 & 1.99 \\
Others & 51 & 6.77 \\
Total & 753 & 100
\end{tabular}


An interrogation and clinical examination of the workers before the chest X-ray revealed that $734(97.47 \%)$ were asymptomatic, 19 workers $(2.52 \%)$ had cough, 16 workers $(2.12 \%)$ had chest pain, 2 workers $(0.26 \%)$ dyspnea and one person $(0.13 \%)$ fever. In addition, there was a history of tuberculosis in 6 workers $(0.79 \%)$, pleurisy in 8 workers $(1.06 \%)$ and pulmonary infection in 18 workers $(2.39 \%)$. 56 cases $(7.43 \%)$ of occasional smoking and alcohol drinking were declared.

Of the 753 radiographs obtained, 712 were normal (94.55\%), while $41 \mathrm{X}$-rays (5.44\%) showed abnormalities (Table 2), thus 14 cases (1.85\%) of blunting of left costophrenic angle, 9 cases (1.19\%) bunting of right costophrenic angle, 8 cases $(1.06 \%)$ of cardiomegaly, 3 cases $(0.39 \%)$ of basal infiltrate, 6 cases $(0.79 \%)$ of apical infiltrate and one case $(0.13 \%)$ of right pleural liquid effusion of mean abundance with right para-tracheal opacity. Among these abnormalities 40 cases (5.31\%) were considered sequelae and one case $(0.13 \%)$ as evolutionary (Figure 2 ).

The figures below show the examples of sequelae (Figures 3-5) and evolutionary (Figure 6) abnormalities encountered.

When the results of the chest X-ray were compared with the clinical signs and the pathological history of the workers, it was found that the only case with evolutionary abnormalities on the chest X-ray showed proven clinical signs, 56.52\%

Table 2. Distribution of patients by chest X-ray results.

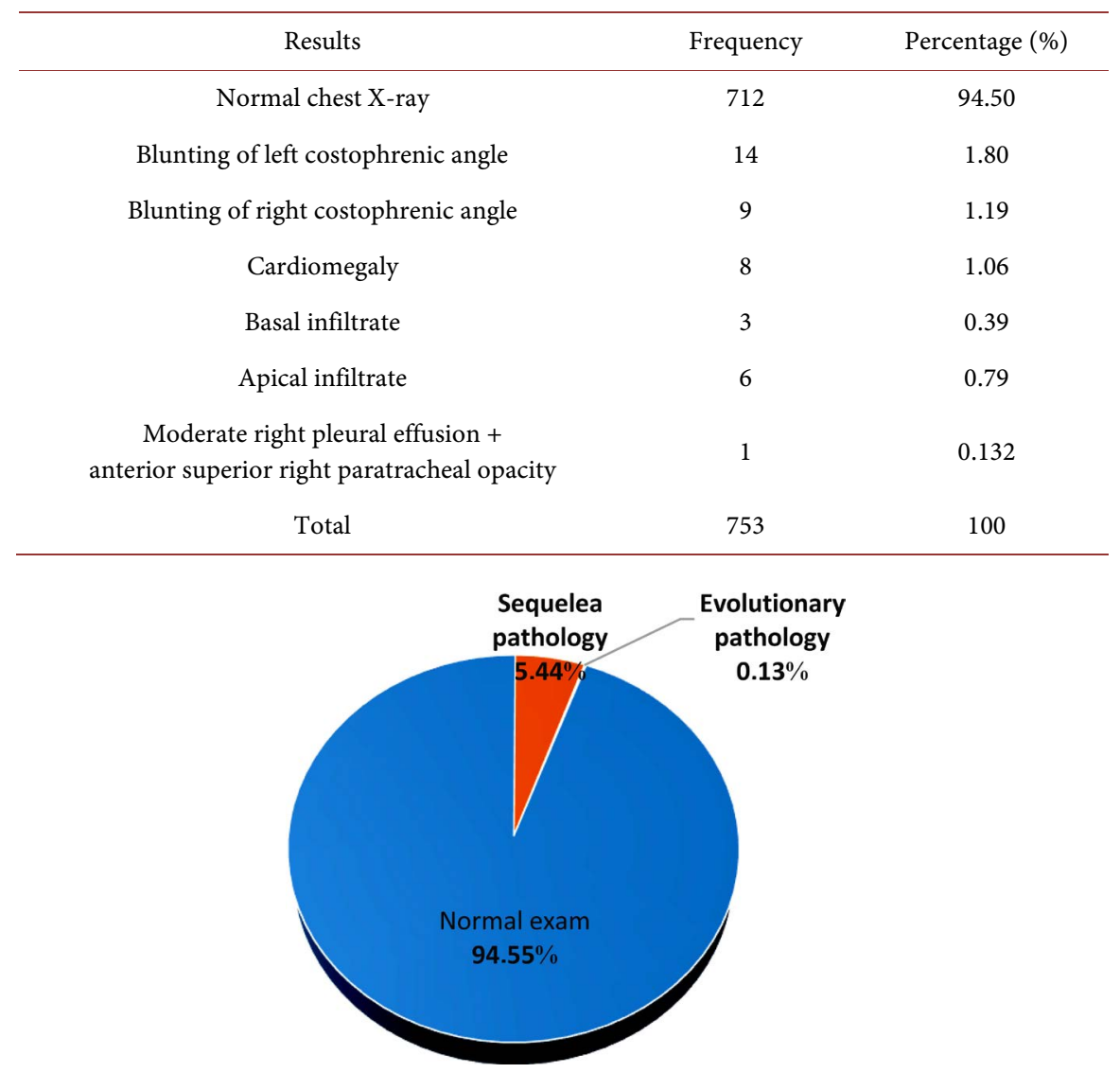

Figure 2. Distribution of pathology by severity. 


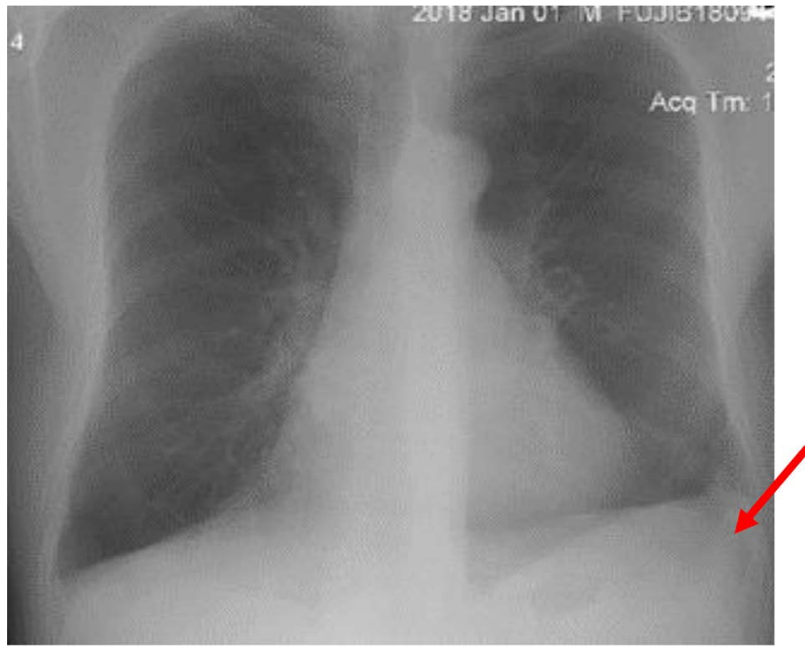

Figure 3. Blunting of left costophrenic angle (red arrow).

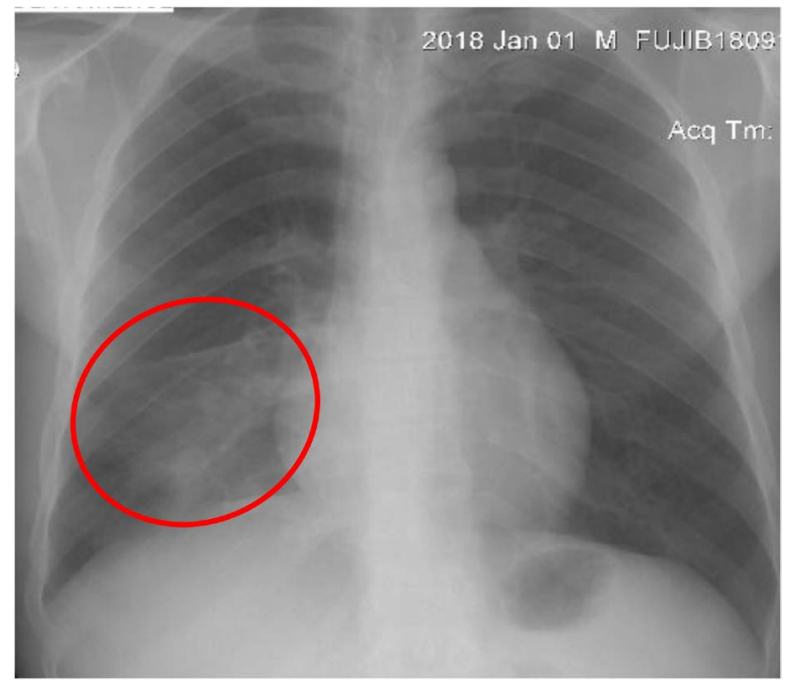

Figure 4. Right basal infiltrate (red circle).

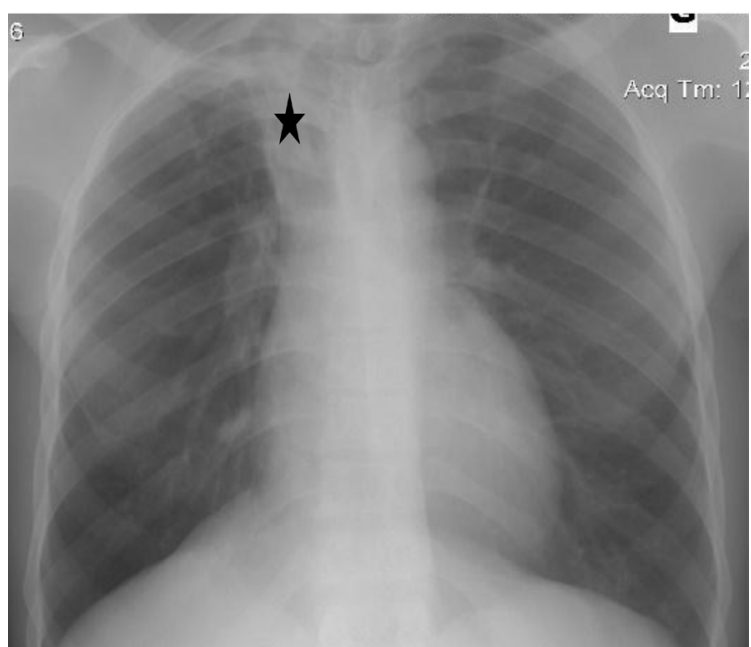

Figure 5. Moderate right pleural effusion (red arrow), anterior superior right paratracheal opacity (black star) and right hilary opacity (red star). 
of the workers with blunting of costophrenic angles on chest X-ray complained of chest pain (Table 3 ) and that one third of those patients had a history of pleurisy, $77.77 \%$ of workers with basal or apical infiltrate had a history of either tuberculosis or lung infection (Table 4). The cost of a single-view PA chest radiograph

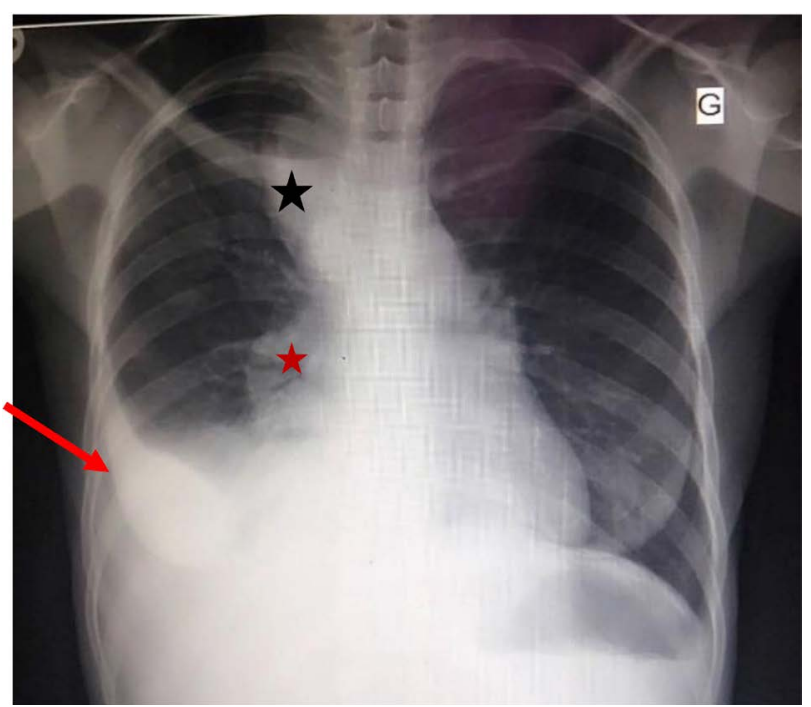

Figure 6. Right apical infiltrate (black star).

Table 3. Distribution of chest X-ray results by clinical signs.

\begin{tabular}{|c|c|c|c|c|}
\hline \multirow{2}{*}{ Results } & \multicolumn{4}{|c|}{ Clinical signs } \\
\hline & Cough & Chest pain & Dyspnea & fever \\
\hline Normal chest X-ray & 17 & 02 & I & I \\
\hline Blunting of left and right costo-phrenic angle & l & 13 & l & l \\
\hline Cardiomegaly & l & I & 01 & l \\
\hline Basal infiltrate & 01 & l & l & l \\
\hline Apical infiltrate & l & l & l & I \\
\hline $\begin{array}{l}\text { Moderate right pleural effusion }+ \\
\text { anterior superior right paratracheal opacity }\end{array}$ & 01 & 01 & 01 & 01 \\
\hline
\end{tabular}

Table 4. Distribution of chest X-ray results by antecedents.

\begin{tabular}{lccc}
\hline \multirow{2}{*}{ Results } & \multicolumn{3}{c}{ Antecedent } \\
\cline { 2 - 4 } & Tuberculosis & Pulmonary infection & Pleurisy \\
\hline Normal chest X-ray & 01 & 10 & 01 \\
Blunting of left and right costo-phrenic angle & $/$ & 02 & 06 \\
Cardiomegaly & $/$ & $/$ & $/$ \\
Basal infiltrate & 01 & 01 & $/$ \\
Apical infiltrate & 04 & 01 & $/$ \\
$\begin{array}{l}\text { Moderate right pleural effusion }+ \\
\text { anterior superior right paratracheal opacity }\end{array}$ & $/$ & 01 & 01 \\
\hline
\end{tabular}


at the Ngaoundere Regional Hospital at the time of the study was 5000 F CFA (\$8.59). The direct cost of all the 753 radiographs obtained was estimated at $3,765,000$ F CFA $(\$ 6,469)$.

\section{Discussion}

Most of the workers in our studied population were men, this was due to the fact that most of the personnel of the companies occupy posts dedicated to men, such as storekeepers, drivers, assistant drivers and mechanics, posts dedicated to few women, hence the low representation of women in this study. With an average age of 39 years, we think that this represents perfectly the majority of people of working age, able to exercise the different trades found in the companies concerned by these periodic medical visits, the majority of these staff was between 30 and 47 years old, about 78\%, Adeko et al. [4] in a study of routine chest X-ray during pre-employment medical visits to health workers found an average age of 26.6 years and from 20 to 49 years was predominant, this difference is due to the fact that in this study the people concerned are still looking for work whereas in our study, they are confirmed workers in different companies. In our series, 712 radiographs were normal or $94.55 \%$ against 41 cases of abnormalities found or 5.44\%, these results are similar to those of Adeko et al. who had found in a study in pre-employment $95.2 \%$ normal radiographs and $4.8 \%$ abnormalities [4], and quite apart from those of Moifo et al. who found $2.5 \%$ of pathologies in a study evaluating the role of routine chest radiography in students during university enrollment in an area endemic for tuberculosis [5].

Among the abnormalities found in our series, one was evolutionary or $0.13 \%$, in a patient with known and proven clinical manifestations, 40 pathologies or 5.31\% were sequelae, as in most studies [5] [7] [8] [9]. Zina-Ebeyard et al. in Gabon found $1.5 \%$ progressive pathologies in a study of 3276 chest X-rays during periodic medical visits [3]. When the results of the chest X-ray were compared with the clinical signs and the pathological history of the workers, it was found that the only case with evolutionary abnormalities on the chest X-ray showed proven clinical signs, $56.52 \%$ of the workers with blunting costo-phrenic angle on chest X-ray complained of chest pain and that one third of these patients had a history of pleurisy, $77.77 \%$ of workers with basal or apical infiltrate had a history of either tuberculosis or pulmonary infection. The medical history and clinical signs for which abnormalities were found on the chest X-ray were history of TB and pleurisy. Some abnormalities on chest X-ray were found in the context of chest pain, dyspnea and fever. For this reason, most authors recommend that chest X-rays should be performed on a case-by-case basis after a clinical examination including a thorough anamnesis and in particular a good interrogation on the known occupational and environmental exposures [3]-[10]. Indeed, these chest X-rays were performed in these apparently healthy patients to detect any occult or occupational disease, such as lung cancer, as soon as possible, so that cure is possible, even if the chest X-ray has been shown to have 
poor sensitivity for the detection of certain diseases, in particular lung cancer and certain infections, consistent with some studies that have shown that screening is not beneficial even in high-risk groups, in addition, normal radiography does not exclude certain infections such as tuberculosis, which is seen in about $15 \%$ of people with normal chest X-rays [11] [12] [13] [14]. Cardiomegaly can be physiological in some people, especially those involved in highly competitive sporting activities.

When exposed to ionizing radiation, the advantages to potential risks should always be carefully considered. If the possible benefits are offset by the potential risks, the procedure can also be considered [5]. We must carefully consider the cost-effectiveness of any diagnostic radiology procedure, particularly in a developing country such as ours, as the expense of resources in procedures with low diagnostic performance would not be cost-effective. The cost of X-rays varies from one country to another, within a country, from one city to another, whatever the cost, the X-ray of the chest must be able to provide a benefit to the patient. In our series, only some patients were able to really benefit from her X-ray, one could really do without X-rays of the chest in other staff.

Our study has some limitations including such as performing a single-incidence chest X-ray, lack of complementary investigations and follow-up of workers with an abnormality, certain conditions such as tuberculosis or cancer could not therefore be excluded in these people.

\section{Conclusion}

The 5.44\% abnormalities rate found in the study appears to be low and calls into question the usefulness and cost-effectiveness of thoracic chest X-ray in periodic medical visits. The only evolutionary pathology was found in a person with proven and known clinical signs. However, patients with lesions on the chest $\mathrm{X}$-ray had clinical signs and antecedents related to these abnormalities, hence the interest of an interrogation and a preliminary clinical examination that could make it possible to discuss the appropriateness of the whether or not the chest $\mathrm{X}$-ray is performed. It should be unsystematic and case-by-case depending on the clinical context and worker history.

\section{Ethical Considerations}

This work was done as part of a master's thesis and we had obtained permission from the university and the hospital, the informed consent of the workers, the anonymity was respected in the context of data collection.

\section{Conflicts of Interest}

The authors declare no conflicts of interest regarding the publication of this paper.

\section{References}

[1] Ministry of Labor and Social Security of the Republic of Cameroon. Law N ${ }^{\circ} 92 / 007$ 
of August 14th, 1992 Bearing the Labor Code Decree $N^{\circ} 79 / 096$ of March 21st, 1979 Fixing the Modalities of Exercise of the Occupational Medicine.

https://www.camerlex.com/cameroun-l-organisation-du-ministere-du-travail-et-de -la-securite-sociale-20647/

[2] College of University Hospital Teachers of Occupational Medicine of Ile-de-France and Labor Inspection of Ile de France. Legislation and Regulations in Occupational Health. January 2006. http://www.uvmt.org/Multimedia/Poly20052006.pdf

[3] Zima-Ebeyard, M.M., Djeki, J., Ondo, Y.S., Nambo-Wezet, G.B. and Obiang Ossoubita, B. (2009) Interest of the Practice of Systematic Chest Radiography during Periodic Medical Visits of Workers in Gabon. CAMIP2009, January-March 2009. http://www.camip.info/Discussion,624.html

[4] Adeko, O.O., Ariba, A.J., Olatunji, A.A. and Toyobo, O.O. (2017) Routine Chest Radiograph in Pre-Employment Medical Examination for Healthcare Workers: Time for a Review of the Protocol. Nigerian Postgraduate Medical Journal, 24, 93-96.

[5] Boniface, M., Joshua, T., Walter, P.E., Fernande, Z.O., Emrick, G.K. and Joseph, G.F. (2012) Assessing the Role of Routine Chest Radiography in Asymptomatic Students during Registration at a University in an Endemic Area of Tuberculosis. Annals of Tropical Medicine and Public Health, 5, 419-422. https://doi.org/10.4103/1755-6783.105122

[6] Doctravail (2011) X-Ray of the Non-Systematic Lungs. The Doctor's Gazette 19 April 2011. http://medecinetravail.canalblog.com/archives/2011/04/19/20931591.html

[7] Nouthe Djubgang, J. and Fayomi, E.B. (1998) Interest of the Practice of the Systematic Pulmonary X-Ray during the Periodic Medical Visits of the Workers in Cameroon. Revue de Médecine du Travail, 25, 95-98.

[8] Jessica, V. (2014) Interest of the Complementary Examinations Carried out and Prescribed during the Systematic Medical Visits. Human Medicine and Pathology. Articles L335.2-L335.10. http://www.dumas.ccsd.cnrs.fr/

[9] Malnick, S., Duek, G., Beilinson, N., Neogolani, V., Basevitz, A., Somin, M., Cohen, J., Katz, M. and Schattner, A. (2010) Routine Chest X-Ray on Hospital Admission: Does It Contribute to Diagnosis or Treatment? The Israel Medical Association Journal, 12, 357-361.

[10] Chukwuani, A.E., Osanaiye, A., Eneje, O.F. and Omiyi, D.O. (2017) An Audit of Routine Chest X-Ray Done During Pre-Employment Medical Screening in South-Western Nigeria. Central African Journal of Public Health, 3, 51-54.

[11] Shah, P.K., Astin, J.H., White, C.S., Patel, P., Haramati, L.B., Pearson, G.D., et al. (2003) Missed Non-Small Cell Lung Cancer: Radiographic Findings of Potentially Resectable Lesions Evident Only in Retrospect. Radiology, 226, 235-241. https://doi.org/10.1148/radiol.2261011924

[12] Fontana, R.S., Sanderson, D.R., Woolner, L.B., Taylor, W.F., Miller, W.E. and Muhm, J.R. (1986) Lung Cancer Screening: The Mayo Program. Journal of Occupational Medicine, 28, 746-750.

[13] Marcus, P.M., Bergstralh, E.J., Fagerstrom, R.M., Williams, D.E., Fontana, R., Taylor, W.F. and Prorok, P.C. (2000) Lung Cancer Mortality in the Mayo Lung Project: Impact of Extended Follow-Up. Journal of the National Cancer Institute, 92, 1308-1316. https://doi.org/10.1093/jnci/92.16.1308

[14] Woodring, J.H., Vandiviere, H.M., Fried, A.M., Dillon, M.L., Williams, T.D. and Melvin, I.G. (1986) Update: The Radiographic Features of Pulmonary Tuberculosis. American Journal of Roentgenology, 146, 497-506.

https://doi.org/10.2214/ajr.146.3.497 